\title{
Recurrent pleural effusion during peritoneal dialysis: answer
}

\author{
Jozef J. M. I. De Dooy • Joanna A. E. van Wijk • \\ Frans B. Plötz • Arend Bökenkamp
}

Received: 8 April 2007 /Revised: 5 June 2007 / Accepted: 5 July 2007 / Published online: 25 September 2007

(C) IPNA 2007

Answers

1. Leakage of peritoneal dialysis (PD) fluid into the pleural cavity.

2. Measurement of the glucose concentration in the pleural effusion.

3. Very high intrathoracic pressure during mechanical ventilation for acute respiratory distress syndrome (ARDS) transiently prevented leakage of PD fluid into the pleural cavity. Reduction of ventilator settings unmasked the pleuro-peritoneal connection with PD fluid leaking through the incision site.

4. To decrease PD dwell volume or temporarily discontinue PD and switch to hemodialysis / hemofiltration.

\section{Commentary}

Hydrothorax - mostly on the right side - is a well-known complication of $\mathrm{PD}$, which is observed in approximately $2 \%$ of all PD patients [1]. In our patient, the glucose

This refers to the article that can be found at http://dx.doi.org/10.1007/ s00467-007-0587-y

J. J. M. I. De Dooy • F. B. Plötz

Departments of Pediatric Intensive Care,

VU University Medical Center,

Amsterdam, The Netherlands

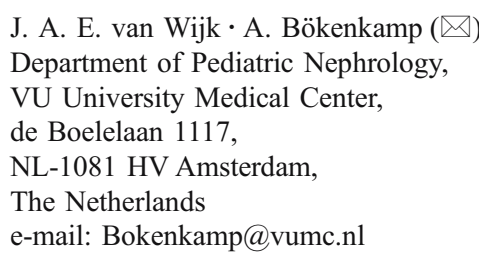

e-mail: Bokenkamp@vumc.nl

concentration in the pleural fluid obtained in the first puncture was $24.9 \mathrm{mmol} / \mathrm{L}(452.7 \mathrm{mg} / \mathrm{dL})$, in the fluid draining from the insertion site four weeks later this was $20.5 \mathrm{mmol} / \mathrm{L}(372.7 \mathrm{mg} / \mathrm{dL})$. Her blood glucose levels were around $10 \mathrm{mmol} / \mathrm{L}(180 \mathrm{mg} / \mathrm{dL})$ during the time of the first puncture and around $7 \mathrm{mmol} / \mathrm{L}(126 \mathrm{mg} / \mathrm{dL})$ on the second occasion. Thus, the intrapleural glucose concentration greatly exceeded the serum values. This finding can only be explained by leakage of PD fluid into the pleural cavity, which ceased transiently during high-pressure ventilation. With these ventilator settings, the intrathoracic pressure exceeded the intraaabdomial pressure thereby preventing peritoneal-pleural shunting.

Usually, demonstration of high glucose concentrations in the pleural fluid is sufficient to confirm a peritoneal-pleural leak [2]. In ambiguous cases - or if no pleural puncture is done - peritoneal-pleural shunting can be demonstrated by adding a radioactive tracer to the dialysate [3, 4]. Although 2 - 4 times higher than the serum concentrations, the intrapleural glucose concentration was still significantly lower than the glucose concentration in the PD fluid, which was $137.5 \mathrm{mmol} / \mathrm{L}(2475 \mathrm{mg} / \mathrm{dL})$. This reflects incomplete equilibration between the fluid collections in both compartments due to inconstant shunting or a small communication between both cavities.

Leakage of PD fluid into the pleural cavity has to be differentiated from other causes of transudative pleural effusion such as congestive cardiac failure, hypoalbuminemia, or fluid overload. In the latter conditions, ultrafiltration is preserved and can typically be increased by using higher PD fluid glucose concentrations. Pleural effusions from a peritoneal-pleural leak typically do not improve with this intervention. In this respect the present case is atypical as ultrafiltration was preserved and could be increased after switch to a higher PD fluid glucose concentration. 
Several mechanisms may lead to the development of a PD-associated pleural effusion, namely congenital diaphragmatic defects, a high peritoneal-pleural pressure gradient and abnormal lymphatic drainage [5]. Butani et al [6] noted a striking association between HUS and pleural effusions in that 7 out of 34 children with HUS but none of 142 children with acute renal failure from other causes developed hydrothorax. The pathophysiological background of their observation is unclear and no other group has yet confirmed their finding.

If possible the first intervention to ameliorate peritonealpleural leakage is to decrease PD dwell volume [7] or to temporarily discontinue PD and switch to hemodialysis/ hemofiltration. This is effective in up to $54 \%[1,8]$. It is recommended to wait around 2 weeks before an attempt is made to switch back to standard PD settings [1,9]. In our patient, the leakage of PD fluid ceased immediately after reduction of the dwell volume to $250 \mathrm{~mL}$.

If this conservative approach fails several treatment options can considered. Instillation of sclerosing agents such as talc or tetracyclines into the pleural cavity causes an inflammatory reaction and pleural fibrosis, which may obliterate the pleuro-peritoneal communication [10]. Alternatively, the diaphragmatic defects can be identified and repaired under direct vision with a surgical approach. Sites of fluid leakage can then be repaired by direct suturing, with or without reinforcement with nonstick (Teflon) felt patches [8]. Pleurodesis in the form of pleurectomy or mechanical pleural abrasion can also be performed during open thoracotomy [11]. In four pediatric cases from a single center, continuous ambulatory peritoneal dialysis (CAPD) could be resumed successfully after surgical thoracotomy. Since the early 1990s, the advantages of video-assisted thoracoscopy over conventional thoracotomy have been increasingly recognized [12]. This minimally invasive procedure permits an excellent visualization of the entire parietal pleura and diaphragm surface with minimal incisions.

This case illustrates that high pressure ventilation can obscure the diagnosis of a peritoneal-pleural leak during
$\mathrm{PD}$, which may only be recognized after weaning from the ventilator.

Acknowledgement The authors wish to thank Prof. Michel Fischbach, Strasbourg (France), for helpful advice on the management of our patient.

\section{References}

1. Chow KM, Szeto CC, Li PK (2003) Management options for hydrothorax complicating peritoneal dialysis. Semin Dial 16:389-394

2. Chow KM, Szeto CC, Wong TY, Li PK (2002) Hydrothorax complicating peritoneal dialysis: diagnostic value of glucose concentration in pleural fluid aspirate. Perit Dial Int 22:525-528

3. Rajnish A, Ahmad M, Kumar P (2003) Peritoneal scintigraphy in the diagnosis of complications associated with continuous ambulatory peritoneal dialysis. Clin Nucl Med 28:70-71

4. Spadaro JJ, Thakur V, Nolph KD (1982) Technetium-99m-labelled macroaggregated albumin in demonstration of trans-diaphragmatic leakage of dialysate in peritoneal dialysis. Am J Nephrol 2:36-38

5. Szeto CC, Chow KM (2004) Pathogenesis and management of hydrothorax complicating peritoneal dialysis. Curr Opin Pulm Med 10:315-319

6. Butani L, Polinsky MS, Kaiser BA, Baluarte HJ (1998) Pleural effusion complicating acute peritoneal dialysis in hemolytic uremic syndrome. Pediatr Nephrol 12:772-774

7. Townsend R, Fragola JA (1982) Hydrothorax in a patient receiving continuous ambulatory peritoneal dialysis: successful treatment with intermittent peritoneal dialysis. Arch Intern Med 142:1571-1572

8. Allen SM, Matthews HR (1991) Surgical treatment of massive hydrothorax complicating continuous ambulatory peritoneal dialysis. Clin Nephrol 36:299-301

9. Leblanc M, Ouimet D, Pichette V (2001) Dialysate leaks in peritoneal dialysis. Semin Dial 14:50-54

10. Chow CC, Sung JY, Cheung CK, Hamilton-Wood C, Lai KN (1988) Massive hydrothorax in continuous ambulatory peritoneal dialysis: diagnosis, management and review of the literature. $\mathrm{N} \mathrm{Z}$ Med J 101:475-477

11. Green A, Logan M, Medawar W, McGrath F, Keeling F, Carmody M, Donohoe J (1990) The management of hydrothorax in continuous ambulatory peritoneal dialysis (CAPD). Perit Dial Int 10:271-274

12. Kawaguchi AL, Dunn JC, Fonkalsrud EW (1996) Management of peritoneal dialysis-induced hydrothorax in children. Am Surg 62:820-824 